\title{
Nanoparticle conversion to biofilms: in vitro demonstration using serum-derived mineralo-organic nanoparticles
}

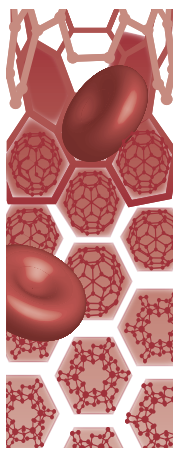

\begin{abstract}
Aims: Mineralo-organic nanoparticles (NPs) detected in biological fluids have been described as precursors of physiological and pathological calcifications in the body. Our main objective was to examine the early stages of mineral NP formation in body fluids. Materials \& methods: A nanomaterial approach based on atomic force microscopy, dynamic light scattering, electron microscopy and spectroscopy was used. Results: The mineral particles, which contain the serum proteins albumin and fetuin-A, initially precipitate in the form of round amorphous NPs that gradually grow in size, aggregate and coalesce to form crystalline mineral films similar to the structures observed in calcified human arteries. Conclusion: Our study reveals the early stages of particle formation and provides a platform to analyze the role(s) of mineralo-organic NPs in human tissues.
\end{abstract}

Keywords: biological fluids $\bullet$ biomineralization $\bullet$ calcium granules $\bullet$ carbonate apatite - ectopic calcification $\bullet$ mineral biofilms $\bullet$ mineral particles $\bullet$ mineralo-organic interface

Ectopic calcification is found in various human conditions, including aging, atherosclerosis, cancer, chronic kidney disease and Type 2 diabetes [1,2]. The presence of vascular calcification correlates with the progression of cardiovascular disease in humans [2], and people with signs of vascular calcification display increased morbidity and mortality risks $[2,3]$. These observations suggest that ectopic calcification is detrimental to human health. Yet the mechanisms regulating ectopic calcification and the formation of calcified deposits remain incompletely understood.

Ectopic calcification in vascular tissues is believed to be initiated by cells that differentiate into osteoblast-like cells and initiate bone formation in response to inflammation or excess calcium and phosphate ions [4,5]. Osteoblast-like cells found in vascular tissues release lipid-bound vesicles, which resemble the matrix vesicles that induce mineralization in developing bones $[4,5]$. Matrix vesicles may concentrate calcium and phosphate ions through the action of transporters and enzymes that release phosphate ions from organic compounds. A core of calcium phosphate similar to the mineral found in bones and teeth forms inside matrix vesicles and is eventually released in the surrounding medium to initiate calcification. While progress has been made in our understanding of vascular calcification, the mechanism of formation of calcified deposits in biological fluids remains unclear.

Several studies have reported the detection of amorphous mineral particles in developing bones and teeth of vertebrates. Höhling et al. [6] and Robinson [7] have observed that round mineral nanoparticles (NPs) represent the first mineral deposited in developing bones and teeth. Similar mineral NPs have been detected in ectopic calcifications found in soft tissues. For instance, Jahnen-Dechent and colleagues have detected fetuin-A-containing calcium phosphate complexes, which this group called 'calciprotein particles,' in ascitic fluids of calcifying peritonitis patients [8]. This group showed that fetuin-A and acidic
Tsui-Yin Wong ${ }^{\ddagger 1,2}$, , HsinHsin Peng ${ }^{\ddagger 1,1,2}$, Cheng-Yeu $\mathrm{Wu}^{1,2,3}$, Jan Martel ${ }^{1,2}$, David M Ojcius ${ }^{2,4}$, Fu-Yung $\mathrm{Hsu}^{5}$ \& John D Young ${ }^{*, 1,2,6,7}$

'Laboratory of Nanomaterials, Chang Gung University, Gueishan, Taoyuan 33302, Taiwan

${ }^{2}$ Center for Molecular \& Clinical Immunology, Chang Gung University, Gueishan, Taoyuan 33302, Taiwan ${ }^{3}$ Research Center of Bacterial Pathogenesis, Chang Gung University, Gueishan, Taoyuan 33302, Taiwan ${ }^{4}$ Department of Biomedical Sciences, University of the Pacific, Arthur Dugoni School of Dentistry, San Francisco, CA 94103, USA

${ }^{5}$ Department of Materials Engineering, Ming Chi University of Technology, Taishan, New Taipei City 24301, Taiwan ${ }^{6}$ Laboratory of Cellular Physiology \& Immunology, Rockefeller University, New York, NY 10021, USA

${ }^{7}$ Biochemical Engineering Research Center, Ming Chi University of Technology, Taishan, New Taipei City 24301, Taiwan

*Author for correspondence: Tel.: +8863211 8800, ext. 3772 Fax: +88632118534 dingeyoung@hotmail.com ${ }^{\ddagger}$ Authors contributed equally 
serum proteins participate in the formation and stabilization of the calcium phosphate complexes, which may transform with time from small spheres to large prolate ellipsoid (i.e., 'secondary calciprotein particles') [8]. A recent study by Bertazzo et al. confirmed the presence of mineral NPs in aortic valves and coronary arteries of both atherosclerotic and rheumatic fever patients [9]. The possibility that such mineral NPs may represent precursors of mineral structures formed in animals and humans remains to be examined.

Our previous studies have shown that mineraloorganic NPs spontaneously form in human and animal body fluids incubated under cell culture conditions [10-23]. These mineralo-organic NPs have helped us to resolve a major controversy concerning the existence of the so-called nanobacteria (NB) mineralized entities initially described as the smallest microorganisms on earth [24] and as the possible cause of various human diseases, including atherosclerosis, cancer, kidney stones, polycystic kidney disease and prostatitis [25-27]. Our work has shown that NB actually represent nonliving mineral NPs that mimic living microorganisms in terms of their shape, growth, proliferation and subculture [11,18]. Mineralo-organic NPs similar to NB have been shown to form not only in human body fluids but also in various organs of the human body, including in the lungs, blood vessels, kidneys and bones (see [22] for a review of the factors controlling particle formation in the body). The possibility that these mineralo-organic NPs may play a role in human diseases is currently under intensive investigation.

We observed earlier that mineralo-organic NPs grow in size and number in biological fluids, forming mineralized structures resembling platelets, spindles and eventually biofilms [11-13]. In the present work, we used a nanomaterial approach to follow the initial stages of particle formation as well as their transformation from amorphous structures to crystalline minerals. We also examined the location of organic molecules within the mineral particles using immunogold labeling and electron microscopy. These results provide important insights for understanding the formation of ectopic calcification occurring in the human body.

\section{Materials \& methods}

\section{Preparation of mineralo-organic NPs}

Human serum (HS) was obtained from healthy volunteers as previously described [11]. The use of human samples was approved by the Institutional Review Board of Chang Gung Memorial Hospital (Linkou, Taiwan). Written informed consent was obtained from the volunteers. HS-NPs were obtained by adding $3 \mathrm{mM}$ each of $\mathrm{CaCl}_{2}$ and $\mathrm{Na}_{2} \mathrm{HPO}_{4}$ into Dulbecco's modified Eagle's medium (DMEM; Gibco, CA, USA) containing $0.1-10 \%$ HS. The resulting solution was incubated under cell culture conditions in an incubator $\left(37^{\circ} \mathrm{C}, 5 \% \mathrm{CO}_{2}\right.$, humidified air) for the time indicated. HS-NPs were pelleted by centrifugation at $16,000 \times g$ for $15 \mathrm{~min}$ at $4^{\circ} \mathrm{C}$ prior to two washing steps using HEPES buffer (20 mM HEPES, $1 \mathrm{mM} \mathrm{CaCl}_{2}, 2 \mathrm{mM} \mathrm{Na} \mathrm{HPO}_{4}, 150 \mathrm{mM} \mathrm{NaCl}$ ) and the same centrifugation conditions. Particles were also prepared by adding $10 \mathrm{mM}$ of $\mathrm{CaCl}_{2}$ and $\mathrm{Na}_{2} \mathrm{HPO}_{4}$ each into DMEM containing $0.1-10 \%$ fetal bovine serum (FBS; Biological industries, Kibbutz Beik Haemek, Isreal), before incubation in cell culture conditions for the time indicated. All ion solutions were adjusted to $\mathrm{pH} 7.4$ and sterilized by filtration through $0.2 \mu \mathrm{m}$ membranes prior to use.

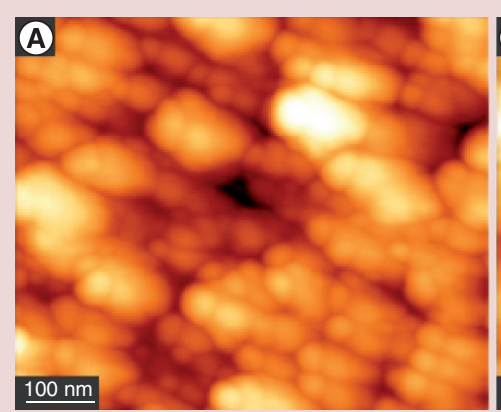

Day 2

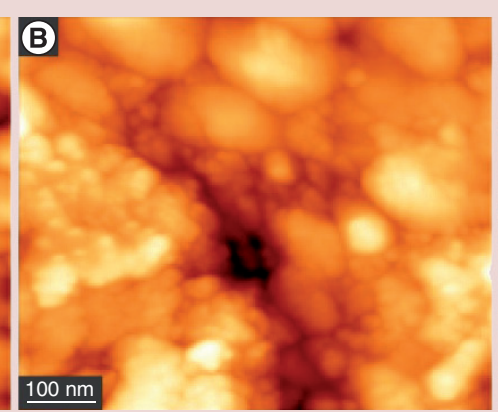

Day 11

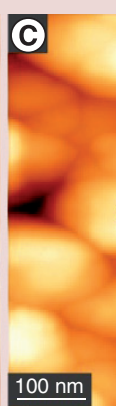

$100 \mathrm{~nm}$

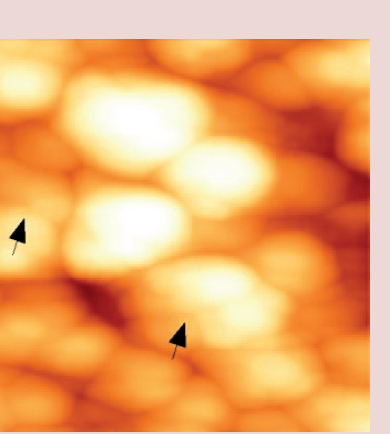

Day 21

Figure 1. Atomic force microscopy observations of mineralo-organic nanoparticles formed in biological fluids. Mineralo-organic NPs were prepared by adding $10 \mathrm{mM} \mathrm{CaCl}_{2}$ and $\mathrm{NaH}_{2} \mathrm{PO}_{4}$ each into $\mathrm{DMEM}$ containing $10 \%$ FBS, followed by incubation under cell culture conditions for (A) 2, (B) 11 and (C) 21 days. Note that the particles increase in size in a time-dependent manner and some appear to fuse during incubation (in $\mathbf{C}$, arrows denote particle fusion lines). 

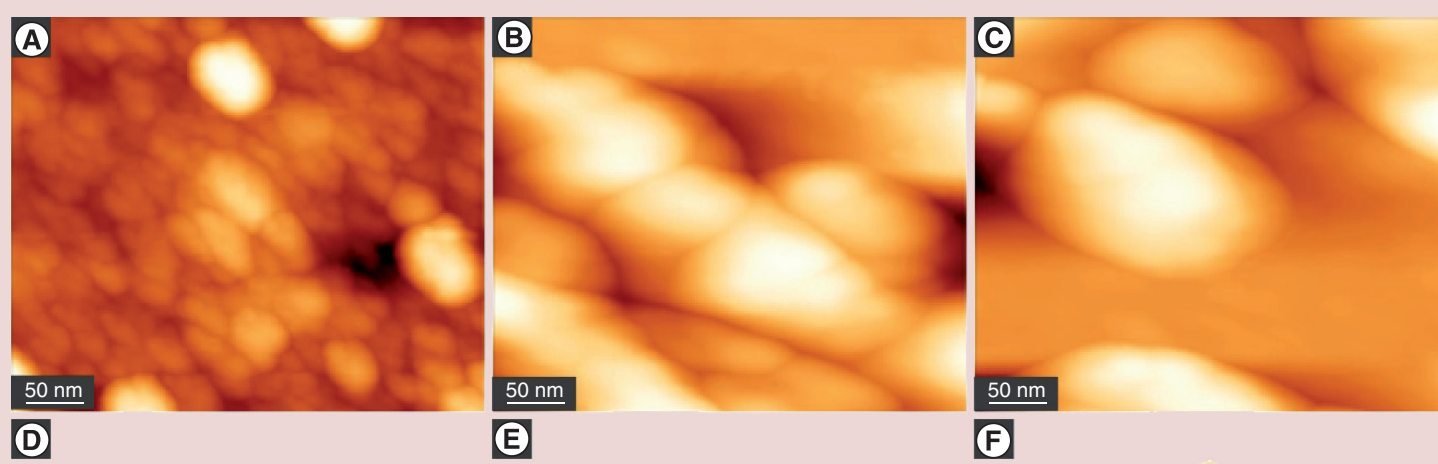

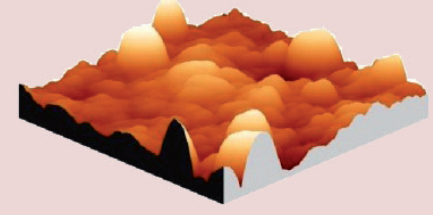

Time 0
傿

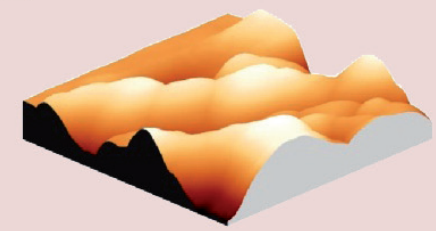

Day 7

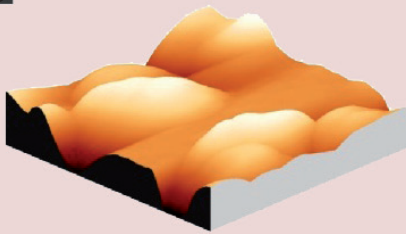

Day 7

Figure 2. Atomic force microscopy observations and 3D surface profiles of mineralo-organic nanoparticle specimens. Mineralo-organic NPs prepared as in Figure 1 were observed by atomic force microscopy, either immediately after mixing precipitating ions at 'Time 0 ' (A) or after incubation in cell culture conditions for 7 days (B \& C). The corresponding 3D surface profiles are shown (D-F). The particles grow in size, fuse and aggregate with time.

\section{Atomic force microscopy}

One drop of particle solution was deposited onto a glass slide, and the sample was air-dried prior to observation under a multimode scanning probe atomic force microscope equipped with a NanoScope IV controller (Veeco, NY, USA). Observations were made at a scan rate of $2 \mathrm{~Hz}$ using a resolution of 512 lines per sample.

\section{Dynamic light scattering measurements}

Dynamic light scattering (DLS) measurements were performed with a Coulter N4 Plus submicron-particle size analyzer (Beckman Coulter, CA, USA). The samples were transferred to disposable plastic cuvettes (Kartell, Milan, Italy) and mixed by gentle inversion. Measurements were performed in triplicate at $25^{\circ} \mathrm{C}$ at an incident angle of $90^{\circ}$.

\section{Transmission \& scanning electron microscopy}

Washed NPs were deposited onto nickel grids (Electron Microscopy Sciences, PA, USA), and excess liquid was removed by using absorbent paper. The grids were dried overnight under a digital desiccator. The samples were visualized without fixation or staining under a JEM 1230 transmission electron microscope (JEOL, Tokyo, Japan) operated at $100 \mathrm{keV}$. Control hydroxyapatite (HAP) consisted of a buffered aqueous suspension ( $25 \%$ solid; Sigma, MI, USA).
For scanning electron microscopy (SEM), washed and dried samples prepared as above were coated with gold for $90 \mathrm{~s}$. The specimens were observed with a field-emission SEM S-5000 scanning electron microscope (Hitachi Science Systems, Tokyo, Japan).

For thin-section transmission electron microscopy (TEM), washed HS-NPs obtained as above were fixed for $4 \mathrm{~h}$ with a solution of $2.5 \%$ glutaraldehyde and $1 \%$ paraformaldehyde in $\mathrm{dd}_{2} \mathrm{O}$ at $4^{\circ} \mathrm{C}$. The particles were washed three-times with $\mathrm{dd}_{2} \mathrm{O}$ for 10 min each time. Pellets containing the particles were dehydrated with successive incubations into $30,50,70,80,90$, 95 and $100 \%$ ethanol, for $10 \mathrm{~min}$ each time. When ethanol at $70 \%$ was used, the particle pellets were incubated at $4^{\circ} \mathrm{C}$ overnight. The other ethanol solutions were only incubated with the pellets for $10 \mathrm{~min}$. Dehydrated particle pellets were incubated with LR white-embedding medium (Electron Microscopy Sciences). Various ratios of ethanol and LR medium (3:1, $1: 1$ and $1: 3)$ were used for 30 min each. Particle pellets were treated with fresh LR medium (100\%) overnight before polymerization. Pellets were incubated at $60^{\circ} \mathrm{C}$ for 2 days to allow polymerization to occur. Blocks of NP samples were sectioned by using a Leica Ultracut UCT microtome. Sections were stained with $4 \%$ uranyl acetate before observation as described above. Electron diffraction patterns were acquired under the same conditions. 
(A)

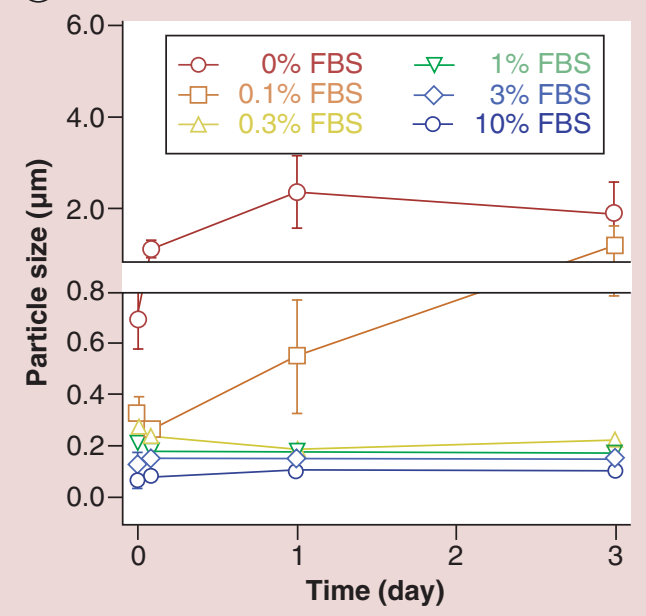

(C)

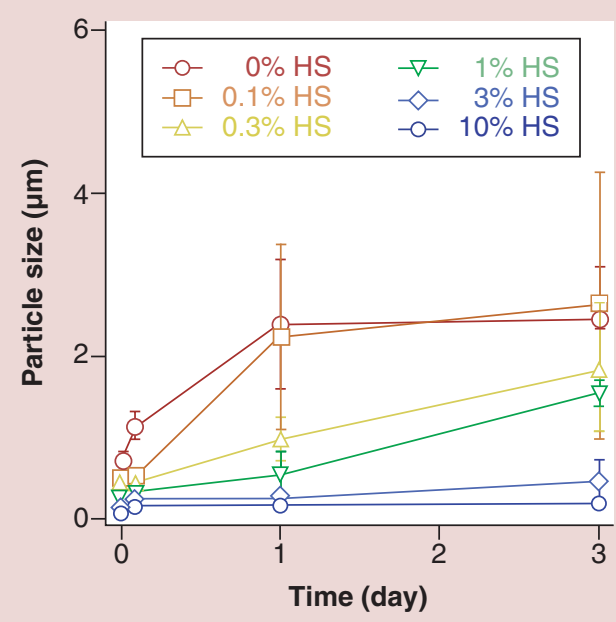

(B)

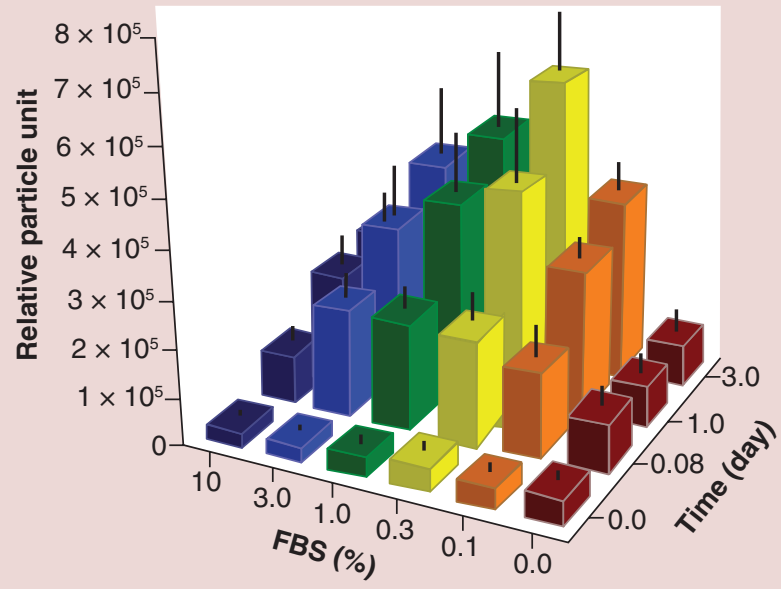

(D)

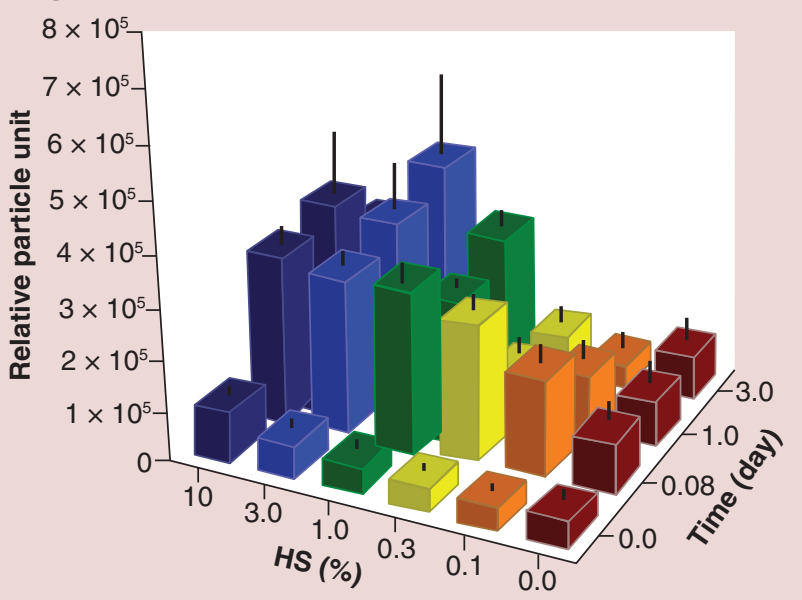

Figure 3. Dynamic light scattering measurements of particle size and number during incubation in biological fluids. (A \& B) Mineralo-organic NPs were prepared by adding $0.7 \mathrm{mM} \mathrm{CaCl}$ and $\mathrm{NaH}_{2} \mathrm{PO}_{4}$ each into DMEM containing FBS at the final concentrations indicated, followed by incubation under cell culture conditions. Particle size (A) and number (B) were determined using DLS. (C \& D) A similar analysis was performed for particles prepared in HS-DMEM. In (B) and (D), the bars and error bars which are masked by other bars of the graph correspond to the following relative particle unit values: $2.0 \times 10^{5} \pm 0.7 \times 10^{5}$ for $10 \%$ FBS, 3 days; $2.5 \times 10^{5} \pm 0.3 \times 10^{5}$ for $10 \% \mathrm{HS}, 3$ days; and $0.8 \times 10^{5} \pm 0.4 \times 10^{5}$ for $0.3 \% \mathrm{HS}, 1$ day.

\section{Production of polyclonal antibodies}

Five hundred micrograms of either albumin or fetuin-A (Sigma) were dissolved into DMEM prior to mixing 1:1 with Freund's complete adjuvant (Sigma). Mixing was performed with two syringes fixed by a 3-way stopcock (Nipro Diagnostics, FL, USA). Solutions were injected intradermally in 3-month-old New Zealand white rabbits. Three weeks after immunization, four boosters ( $200 \mu \mathrm{g}$ of protein mixed with a 1:1 solution of DMEM and incomplete Freund's adjuvant) were injected at a 1-month interval. Venous blood was collected from the ear vein. For apo-A1, 30-kDa SDS-PAGE bands corresponding to $200 \mu \mathrm{g}$ of protein from whole serum were used for injections as described above.

\section{Immunogold staining}

Mineralo-organic particles were prepared as for TEM observation. HS-NPs embedded in resin were cut into slices of $<70$-nm thickness. Samples deposited on grids were blocked with $1 \%$ fish gelatin (Sigma) in $0.1 \mathrm{M}$ HEPES buffer at $\mathrm{pH} 8.0$ for $30 \mathrm{~min}$. Grids were incubated with anti-human serum albumin ( $\alpha$-HSA; $1: 30)$, anti-human serum fetuin-A ( $\alpha$-HSF; $1: 50-1: 70)$, antiapolipoprotein-A1 ( $\alpha$-apo-A1; $1: 30)$ and anti-HSNP ( $\alpha$-HS-NP; 1:60) antibodies. Negative controls received no primary antibody. Sections were washed with HEPES buffer for $15 \mathrm{~min}$. Washed samples were blocked with $1 \%$ fish gelatin in HEPES buffer for $10 \mathrm{~min}$. Specimens were treated with the secondary 
5-nm-gold-conjugate goat anti-rabbit $\operatorname{IgG}(1: 20-1: 60)$ for $1 \mathrm{~h}$. Specimens were washed with HEPES buffer and $\mathrm{dd}_{2} \mathrm{O}$ for $10 \mathrm{~min}$ each. TEM observations were done as described above.

\section{Energy-dispersive $\mathrm{X}$-ray analysis}

NP specimens were prepared as for thin-section TEM observation without staining. Energy-dispersive X-ray (EDX) spectra were obtained with a high-resolution JEM 2100 transmission electron microscope (JEOL) operated at $120 \mathrm{keV}$. EDX spectra were acquired in triplicate using an INCA Energy EDS system (Oxford Instruments, UK).

\section{Powder X-ray diffraction analysis}

Washed particle samples were resuspended in $\mathrm{ddH}_{2} \mathrm{O}$ and deposited on glass slides for dried overnight under a laminar flow hood. X-ray diffraction (XRD) analysis was performed by using a Bruker AXS D5005 X-ray diffractometer (Bruker, WI, USA). Spectra were compared with the database of the Joint Committee on Powder Diffraction and Standard for chemical formula identification.

\section{Results}

Formation of mineralo-organic NPs in biological fluids

To characterize the development of mineral particles in biological fluids, we first prepared mineraloorganic NPs by adding calcium and phosphate ions to cell culture medium (e.g., DMEM) containing FBS. We described this precipitation method earlier [11] to study mineralo-organic NPs similar to the mineral particles detected in human tissues [8] and to the socalled NB [24-27]. We also studied earlier in detail the main factors that influence particle formation, including $\mathrm{pH}$, temperature and ion and serum concentrations [11-13]. In the present study, we first observed the NP samples under atomic force microscopy (AFM) in order to visualize the mineralization process occurring at the nanoscale $(<100 \mathrm{~nm})$.

The mineral particles were observed at various times during incubation in cell culture (Figure 1A-C). Two days after precipitation, the mineralo-organic NPs consisted of spherical or ovoidal particles ranging from 50 to $250 \mathrm{~nm}$ in diameter (Figure 1A). Particle size gradually increased during incubation (Figure 1B, 11 days), eventually reaching sizes of approximately 100-350 nm after 3 weeks (Figure 1C). With time, the particles fused and formed larger mineral aggregates, as seen by the presence of fusion lines in adjacent particles (Figure 1C, arrows).

In order to observe the initial stages of particle formation, we examined particle specimens immediately following precipitation (Figure 2A). Mineral particles that had just formed were of relatively small size, ranging between 25 and $100 \mathrm{~nm}$ in diameter (Figure 2A). The smallest particles had a poorly defined border (Figure 2A), compared with mature particles (Figure 2B \& C, 1 week). The corresponding $3 \mathrm{D}$ surface diagrams confirmed that the particles increased in size and coalesced to form larger mineral aggregates (Figure 2D vs E \& F). After 1 week of incubation, large mineral aggregates that had fused together were observed (Figure 2B, C, E \& F). These

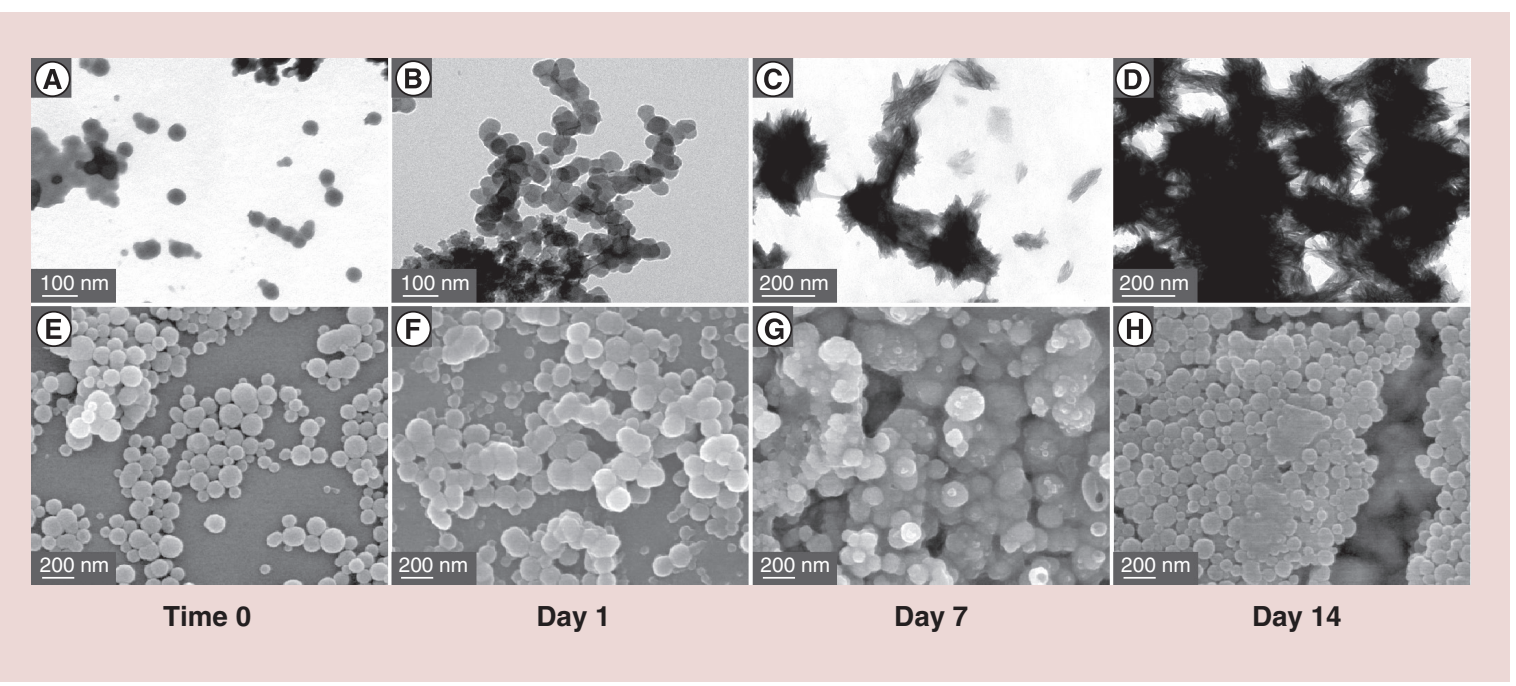

Figure 4. Electron microscopy observations of mineralo-organic nanoparticles during incubation in cell culture. Mineralo-organic NPs derived from FBS-DMEM as described in Figure 1 were prepared for TEM without fixation, embedding or staining (A-D) and for SEM (E-H) immediately after precipitation (time 0 ) or following incubation in cell culture conditions for 1, 7 and 14 days as indicated. Initially, round and distinct following precipitation (time 0 ), mineral particles gradually fused and aggregated with time (day 1), eventually forming mineralized biofilm-like structures (days 7 and 14). 


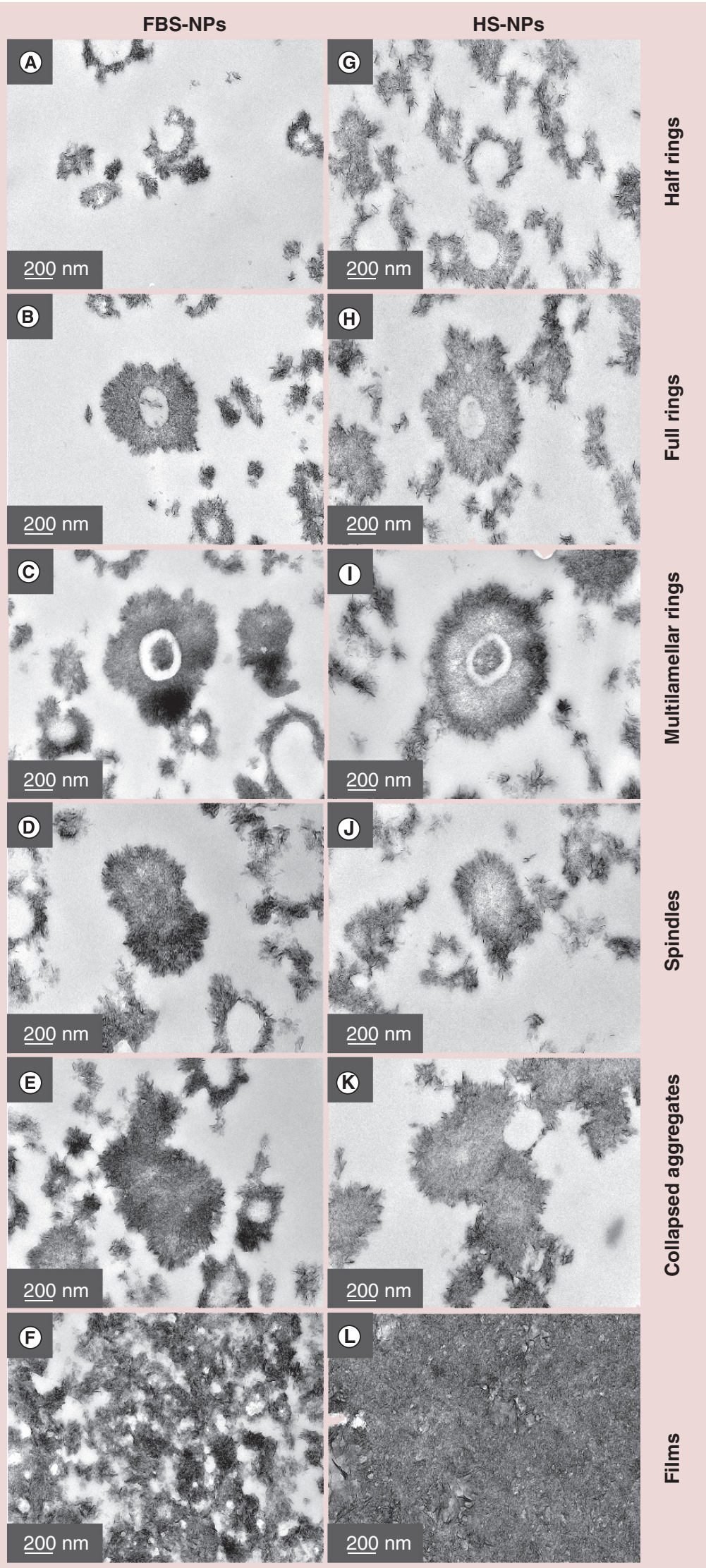


Figure 5. Morphologies of mineralo-organic nanoparticles during incubation in culture (see facing page). Mineralo-organic NPs were prepared by adding $\mathrm{CaCl}_{2}$ and $\mathrm{Na}_{2} \mathrm{HPO}_{4}$ at $3 \mathrm{mM}$ each into DMEM containing either $1 \%$ FBS (A-F) or $10 \% \mathrm{HS}(\mathrm{G}-\mathrm{L})$ prior to incubation under cell culture conditions for 1 month. After incubation, FBSNPs and HS-NPs were harvested and prepared for thin-section TEM. In samples prepared from either FBS or HS, mineral NPs formed rings, spindles, aggregates and films. Ring structures showed a hollow cavity while spindles were solid and fully mineralized. Collapsed aggregates showed a mineralized surface with longer crystalline projections compared with spindles. Mineralized films contained large (F) or small voids (L), depending on the samples examined.

observations suggest that mineralo-organic NPs initially form through an amorphous liquid-like precursor that gradually increases in size and coalesces with time to form larger mineral precipitates.

\section{Measurements of particle size \& number in culture}

To confirm the increase in size observed under AFM, we monitored particle size in liquid samples using DLS. Particles obtained after addition of precipitating ions in DMEM containing no FBS measured $0.7 \mu \mathrm{m}$ in size and increased to $2.4 \mu \mathrm{m}$ after $24 \mathrm{~h}$ of incubation (Figure 3A, 0\% FBS). Particle size decreased in a dose-dependent manner following addition of FBS (Figure 3A, 0.1-10\% FBS), consistent with the presence of calcification inhibitors such as albumin and fetuin$\mathrm{A}$ in serum $[11,14,28-31]$. Some particles such as the ones produced with 0.3 and $1 \%$ FBS did not grow with time and even appeared to slightly decrease in size during the first $24 \mathrm{~h}$ of incubation (Figure 3A). Solutions containing $10 \%$ FBS produced mineral NPs smaller than 100 $\mathrm{nm}$, and the particles grew slowly during the first $24 \mathrm{~h}$, remaining stable thereafter (Figure $3 \mathrm{~A}$ ).

We also quantified the proliferation of particles incubated in biological fluids using DLS. The number of particles in DMEM containing no FBS increased after precipitation before decreasing to low levels at days 1 and 3 (Figure 3B, 0\% FBS). In contrast, particle number obtained in the presence of FBS gradually increased for the first $24 \mathrm{~h}$ (Figure 3B, $0.1-10 \% \mathrm{FBS}$ ). Addition of FBS from 0 to $0.3 \%$ increased the particle number in a dosedependent manner, while the addition of FBS above this concentration produced a dose-dependent decrease in the number of particles (Figure 3B). Similar results were obtained for HS-NPs, although HS promoted production of larger particles (Figure $3 C \& D$ ), consistent with the high calcification inhibitory effect of FBS compared with HS [11]. These observations are in agreement with the seeding-inhibition concept described in previous studies [11,13]. According to this model, serum used at low concentrations can seed mineral particles while high concentrations inhibit particle formation.

\section{Electron microscopy observations of mineral particle-to-film conversion}

We next observed the morphology of mineralo-organic particles under TEM without fixation or staining
(Figure 4A-D). Upon formation, mineralo-organic NPs appeared as small round particles that were either dispersed or forming aggregates (Figure 4A). During incubation in biological fluids, the particles gradually increased in size and tended to aggregate further (Figure 4B). Strings of particles were also observed (Figure 4B), consistent with the fusion of particles observed earlier (Figure 1C) or the possibility that the particles may serve as nucleators for particle formation by secondary nucleation. With time, the particles gradually crystallized and coalesced (Figure 4C) to form crystalline mineral films (Figure 4D). Observations by SEM confirmed the phenomenon of particle-to-film conversion as seen by the gradual increase in the size and number of the particles, until they formed film-like structures (Figure 4E-H).

We also prepared thin sections of the mineraloorganic NPs for observation by TEM (Figure 5A-L). In samples of mineralo-organic NPs prepared in FBS (FBS-NPs), we initially observed half-ring and full-ring particles (Figure 5A \& B). These particles evolved to form multilamellar rings (Figure $5 \mathrm{C}$ ), before crystallizing further into spindles (Figure 5D). The particles then gradually coalesced and aggregated (Figure $5 \mathrm{E}$ ) to form mineral films (Figure 5F). Similar results were obtained when the particles were prepared in HS (Figure 5G-L, HS-NPs). However, the HS-NPs shown here were prepared using $10 \%$ HS instead of $1 \%$ FBS for FBS-NPs, confirming our previous observations that FBS produced smaller particles compared with HS (Figure 3). Using various electron microscopy techniques, we thus show here that mineralo-organic NPs undergo a particle-to-film conversion in biological fluids.

\section{Ultrastructural localization of calcification inhibitors in mineralo-organic NPs}

We observed previously that albumin and fetuinA constantly interact with mineralo-organic NPs formed in various human body fluids including serum [11-13]. In order to determine the location of these proteins within mineralo-organic NPs and their possible mode of interaction with the mineral phase, we used immunogold labeling coupled with thinsection TEM. In order to maximize the detection of mineralo-organic NPs, we prepared rabbit polyclonal antibodies against mineral particles that had formed in the presence of albumin and fetuin-A. We verified 


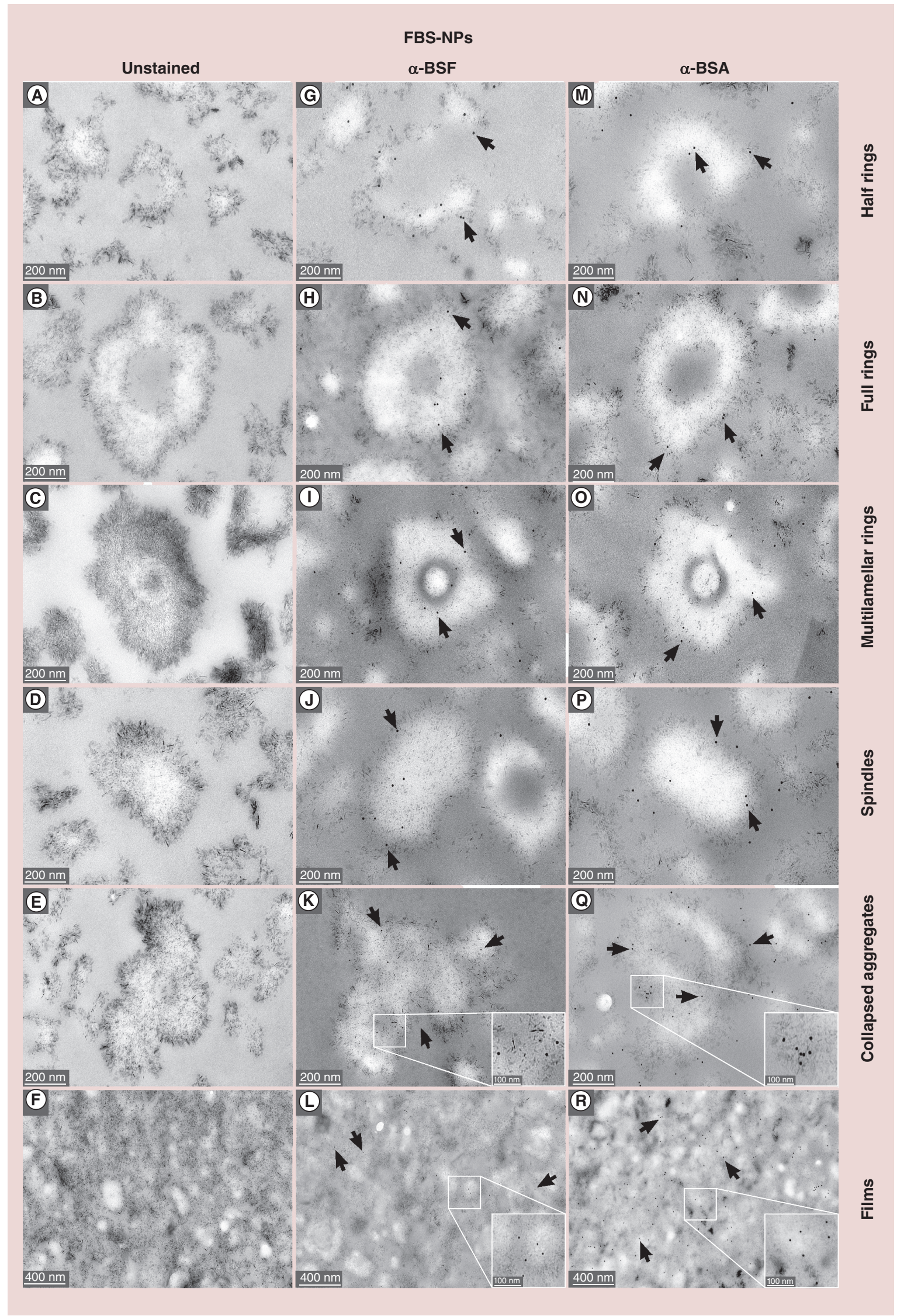


Figure 6. Immunogold staining of fetal bovine serum-nanoparticles incubated in body fluids (see facing page). Mineralo-organic NPs were prepared as in Figure 5, using FBS at 1\%. After incubation in cell culture conditions for 1 month, the particles were prepared for thin-section TEM and immunogold staining (A-F). Thin sections were treated with primary antibodies against fetuin-A (G-L) or albumin (M-R). The secondary antibody alone was used as negative control ('unstained' column). Arrows denote gold NPs bound to mineral particles. Every evolution stage of mineralization stained positively with the gold-conjugate antibodies directed against either BSF or BSA. Staining was observed mainly in the electron-dense phase of the particles and films. In the case of ring structures, both the surface and the inner cavities of the particles were stained with the gold-conjugated antibodies.

earlier the antibodies' specificity using Western blotting (see [32] for experiments showing the specificity of the antibodies against human proteins; similar results were obtained for the corresponding bovine antibodies against bovine proteins; data not shown).

Using the polyclonal antibodies directed against particles prepared in FBS, we observed that albumin and fetuin-A were associated with every growth stage of the mineral particles (Figure 6G-R, unstained particles are shown in Figure $6 \mathrm{~A}-\mathrm{F}$ ). In half-ring samples, albumin and fetuin-A appeared to be concentrated on the surface of the particles (Figure $6 \mathrm{G} \& \mathrm{M}$ ), while later particle stages showed proteins situated both on the surface and inside the mineral particles (Figure $6 \mathrm{H}-\mathrm{L} \& \mathrm{~N}-\mathrm{R}$ ). In late stages, the two serum proteins appeared to be associated mainly with the dark areas of the mineralo-organic particles (Figure 6I-L \& O-R), indicating that this zone may contain larger amounts of organic molecules, compared with electron-lucent areas. Similar results were obtained for particles prepared in HS (Figure 7, HS-NPs).

Spectroscopy analysis of mineralo-organic NPs We next studied the chemical composition and crystallographic properties of the mineralo-organic particles formed in body fluids. Using EDX, we observed major peaks of carbon $(\mathrm{C})$, calcium $(\mathrm{Ca})$, oxygen $(\mathrm{O})$ and phosphorus $(\mathrm{P})$ in the spectra of the particles (Figure 8G \& N). Minor peaks corresponding to sodium $(\mathrm{Na})$, zinc $(\mathrm{Zn})$, silicon $(\mathrm{Si})$ and nickel $(\mathrm{Ni})$ were also observed (Figure 8G \& N, note that the presence of $\mathrm{Ni}$ may be due at least in part to the grids used as a support for this analysis). This EDX profile was consistent with the presence of calcium phosphate within the mineral particles. The $\mathrm{Ca} / \mathrm{P}$ atomic ratios of the representative FBS-NP and HS-NP samples shown here were 1.47 and 1.15 , respectively (Figure 8G \& N). These values are similar to the theoretical value of 1.67 for pure, stoichiometric HAP [11], the crystal found in bones and teeth of vertebrates [33]. As described earlier [11], the minor variability of the $\mathrm{Ca} / \mathrm{P}$ ratios measured for mineralo-organic NPs could be attributed to incomplete crystallization or the presence of impurities and ion substitutions within crystal lattices.

We used selected area electron diffraction analysis (SAED) and compared the diffraction patterns obtained for the various growth stages. Mineraloorganic NPs collected immediately after precipitation showed a pattern of poorly crystallized mineral (Figure 8A \& B, note that concentric rings are barely visible on the patterns in the insets), while particles cultured in biological fluids for several days produced polycrystalline diffraction patterns (Figure $8 \mathrm{C}-\mathrm{F}$, rings can be clearly observed on these patterns). Similar results were obtained for particles prepared in HS (Figure $8 \mathrm{H}-\mathrm{M}$ ). FBS-NPs and HS-NPs showed diffraction patterns consistent with the presence of a polycrystalline material of relatively small crystal size, whereas commercial HAP used as control produced a pattern representing single crystals of large size (Figure 9A \& B vs C). Besides, interplanar d-spacing values of the $d_{(002)}$ reflection calculated for HS-NPs and FBS-NPs (i.e., 0.340 and $0.346 \mathrm{~nm}$, respectively) were similar to that of HAP $(0.348 \mathrm{~nm})$, thus suggesting that the mineral phase observed for these NPs may represent HAP.

We also used powder XRD analysis in order to study the development of mineralo-organic NP samples during incubation under cell culture conditions (Figure 10). We observed that mineralo-organic NPs were initially amorphous following precipitation (Figure 10A), but eventually crystallized during incubation to form calcium phosphate (Figure 10B) and HAP crystals (Figure 10C \& D). Based on these results, we conclude that mineralo-organic particles form from a poorly crystallized calcium phosphate mineral precursor of small size that gradually converts with time into crystalline HAP.

\section{Discussion}

While ectopic calcification is associated with numerous human diseases, the factors that induce the formation of calcified deposits in biological fluids remain poorly understood. In the present study, we show that mineral NPs that form in biological fluids gradually develop into a mineralized biofilm-like structure during incubation in cell culture conditions. This mineral biofilmlike structure is similar to the calcified deposits found in human arteries and other tissues, and we therefore believe that the particle-to-film progression described here may serve as a model for studying the factors that induce ectopic calcification in vivo. For instance, the development of mineral biofilms may be used as an 


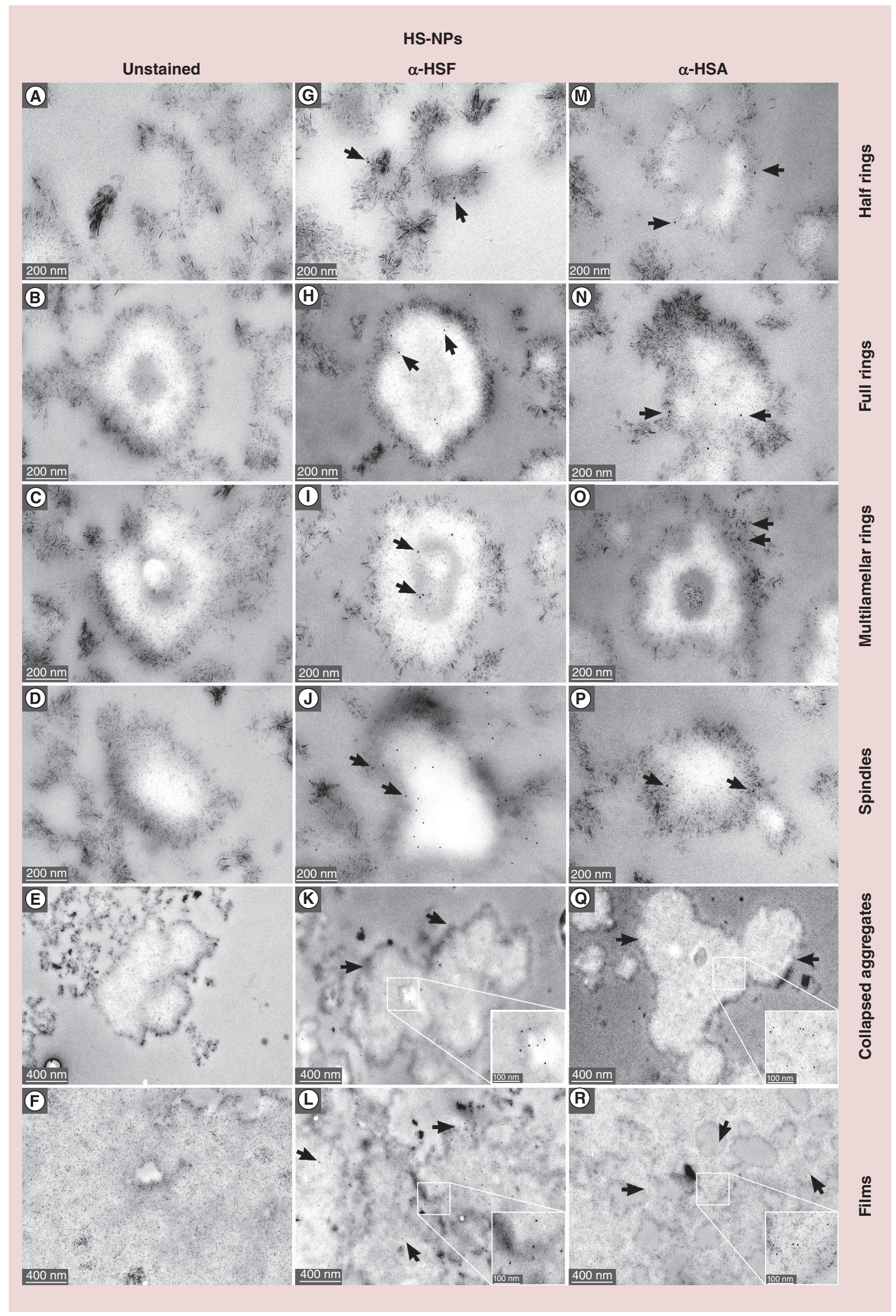


Figure 7. Immunogold staining of human serum-nanoparticles incubated in body fluids (see facing page). Mineralo-organic NPs were prepared as in Figure 5, using $10 \%$ of HS. Following incubation, the particles were prepared for thin-section TEM and immunostaining. The samples were treated with anti-fetuin-A antibody (G-L) or anti-albumin antibody (M-R). The secondary antibody alone was used as a negative control (A-F). Arrows denote gold NPs. As seen for FBS-NPs in Figure 6, all mineralization stages stained positively with gold-conjugate antibodies directed against either BSF or BSA. Gold particles were noted mainly within the electron-dense phase of the particles and films. Both the surface and the inner cavities of the ring structures were stained with the gold-conjugated antibodies.

assay to screen for possible compounds that can inhibit the formation of mineral biofilms. These experiments may prove helpful for developing treatments that can prevent ectopic calcification and formation of kidney stones.

Our results support the notion that mineralo-organic NPs represent precursors of mineralization in the human body. These NPs have been repeatedly detected in both physiological and pathological calcification processes in vivo (reviewed in [22]). Protective mechanisms may be at work in vivo to limit the formation and crystallization of these particles in soft tissues in the healthy state. For instance, calcification inhibitors such as pyrophosphate or proteins like albumin, fetuin-A, matrix gla protein and osteopontin, may prevent the precipitation of calcium phosphate in body fluids [34,35]. In addition, macrophages of the reticuloendothelial system are believed to continually remove these mineral particles from circulation. Accordingly, Jahnen-Dechent and colleagues showed that mice deficient for fetuin-A show microscopic calcification when fed a mineral-rich diet [36]. In addition, it was shown that mineralo-organic NPs, which this group refers as 'calciprotein particles,' are rapidly removed from the circulation by macrophages of the spleen and liver following intravenous inoculation in mice [37]. The recognition that mineral NPs represent the first stage of calcification may eventually help us to better recognize and prevent this condition, before macroscopic-calcified deposits are detected in the body.

Formation of mineral biofilms requires the presence of an amorphous mineral phase which appears to possess characteristics similar to a liquid phase. The progression from amorphous mineral to a crystalline phase has attracted considerable attention in recent years, and the amorphous mineral phase is now recognized to be involved in the formation of various biomineralization processes [38-40]. We observed that minerals that precipitate in the presence of organics form round amorphous mineral particles that possess biomimetic properties and undergo an amorphous-to-crystalline transition. We referred to these particles as 'bions' to denote the various ions that can contribute to their composition as well as the biological nature of the particles [20]. It should be noted that our use of the term bions is different from that of Reich who coined the term in the late 1930 s to describe putative living or preliving vesicles isolated from decaying grass, soil and animal matter [41] (these findings have to our knowledge never been reproduced in any major scientific journal). Further studies are currently under way to determine the possible role of amorphous minerals and bions in biomineralization processes including bone formation and ectopic calcification.

Our results show that mineralo-organic NPs can form round multi-ring particles. These multi-ring particles continually form alternating electron-dense and electron-pervious layers. Amos et al. [42] produced similar multi-ring mineral particles in vitro by inducing mineral precipitation in the presence of anionic polypeptide additives. Evan et al. [43] and Ryall [44] have proposed that the electron-dense layers of multilamellar particles observed in human kidney tissues may represent organics, while the electron-pervious layers may correspond to minerals. Consistent with these results, we observed in the present study that albumin and fetuin-A are mainly located in dark, electron-dense layers of the particles. Previous studies performed by us [11-13,16] and others [8,28-31,34-36,45] have shown that albumin and fetuin-A are consistently associated with calcium phosphate mineral particles and that these proteins favor the formation of spherical, amorphous NPs. These observations and the identification of the proteins found in the electron-dense layers of the NPs may facilitate the identification of mineral particles in human tissues.

Another area of interest is the study of the interactions between the mineralo-organic NPs described here and cells found in the human body. We have shown earlier [19] that mineralo-organic NPs are internalized by human macrophages and that large particles or particle aggregates with a diameter above $1 \mu \mathrm{m}$ induce the secretion of pro-inflammatory IL-1 $\beta$ by these cells. We also reported that mineralo-organic particles activate the release of neutrophil extracellular traps (NETs) and that the NETs released by neutrophils may in turn induce the secretion of TNF- $\alpha$ by bystander macrophages [Peng HH et al. Mineralo-organic particles induCE INNATE IMMUNity through NeUtrophil extracellular traps containing hmgbl (2015), Submitted]. A recent study by Chen et al. [46] also showed that calcium phosphate NPs similar to the ones described in the present study induce the differentiation of rat bone marrow stromal cells into osteoblast-like cells. Besides, interactions between mineralo-organic NPs and the extracellular 


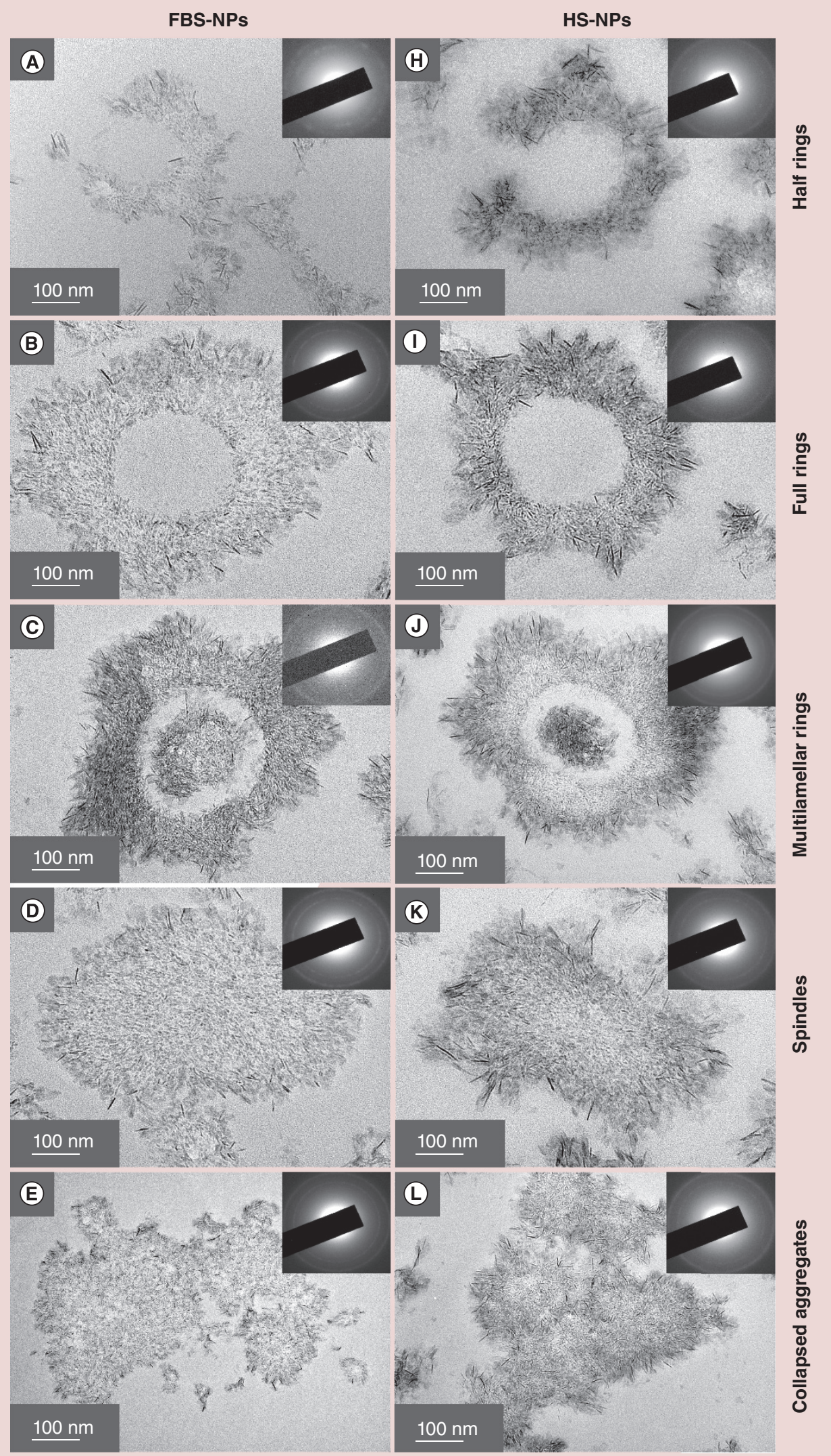



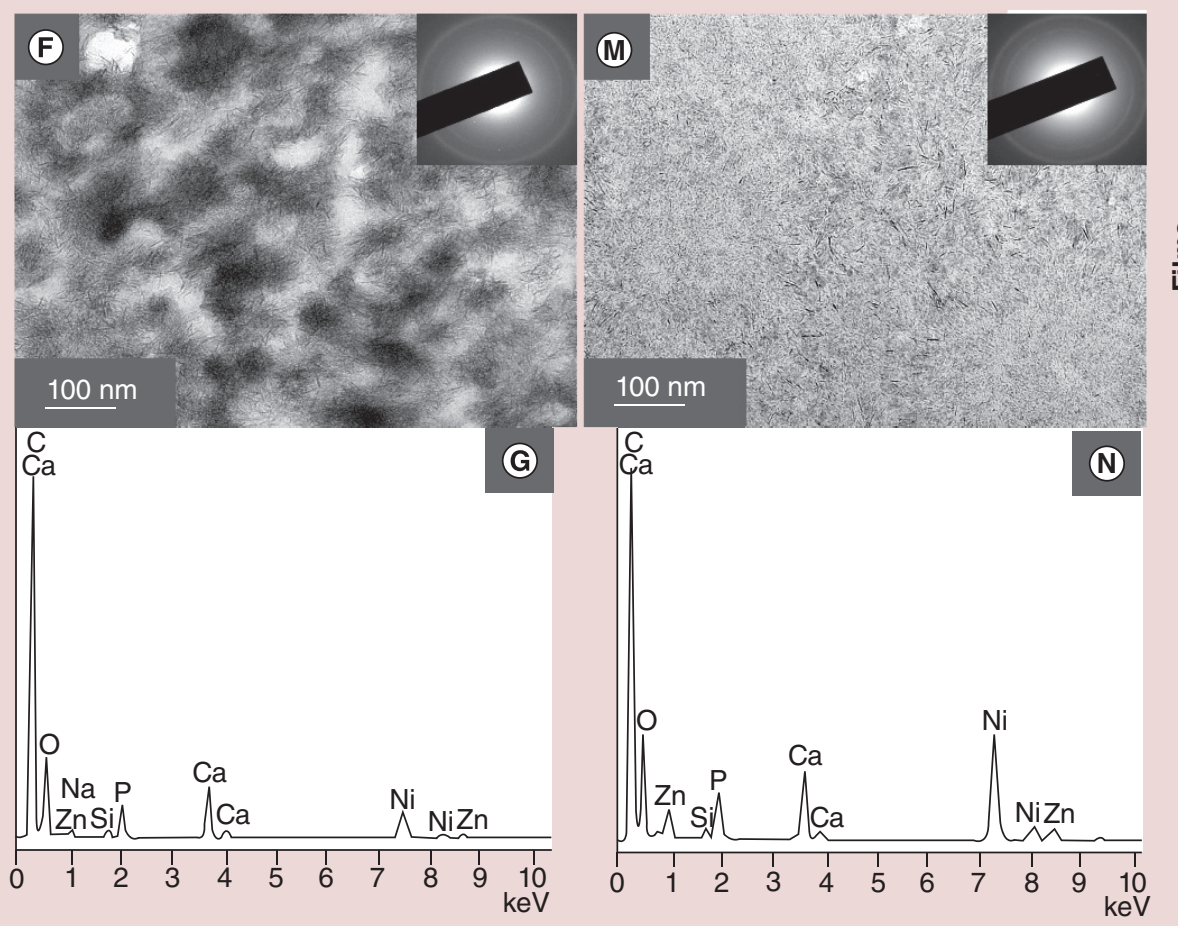

Figure 8. Selected area electron diffraction analysis of mineralo-organic nanoparticles prepared in serum (see also facing page). Mineralo-organic NPs were prepared as in Figure 5, using either $1 \%$ FBS (A-G) or $10 \%$ $\mathrm{HS}(\mathrm{H}-\mathrm{N})$. Following incubation, the particles were prepared for thin-section TEM and SAED analysis. Electron diffraction patterns (insets at the top right of each TEM image) revealed that the forming particles were initially poorly crystalline and gradually converted into polycrystalline mineral particles. EDX analysis suggested that the particles consist of calcium phosphate containing minor additional elements (G \& N).

matrix also represent a topic worthy of further studies as seen by the observation that extracellular matrix proteins control the formation of calcium phosphate particles during bone and tooth formation [47], and these proteins may also play a role in ectopic calcification. Further studies are needed to examine these phenomena in more detail.

A previous study by Schwartz et al. examined the effects of various biochemical treatments on the formation of mineral biofilms derived from calcified human samples [48]. This study showed that RNAse failed to influence biofilm formation while the antibiotic drugs gentamycin and tetracycline completely inhibited this process [48]. In addition, the same study showed that mineral biofilms stained with concanavalin A (a carbohydrate-binding protein or lectin) and BacLight green (a commercial kit used to differentiate living bacteria from dead ones). While such results give the impression that living and enzymatic processes are necessary for the formation of mineral NPs and biofilms, we have shown here that mineralized biofilms can be derived from the precipitation of inorganic mineral NPs in the presence of organic molecules derived from body fluids. This conclusion is consistent with our previous observations that NB and calcifying NPs represent non-living mineral NPs that mimic living organisms in various ways $[14,18]$. Accordingly, we have shown that the whole NB phenomenology can be re-interpreted in terms of the interactions between minerals and organic moieties found in body fluids $[11,14,18]$. This simple explanation can fully account for the observations of NB and calcifying NPs in the human body and biological fluids.

\section{Conclusion}

We have shown that mineralo-organic NPs similar to the particles described in human tissues differentiate to form mineral biofilms during incubation in biological fluids. The serum proteins albumin and fetuin-A are associated with all growth stages of mineralo-organic NPs derived from body fluids, especially with the electron-dense phase of the particles. These findings support the concept that the mineralo-organic NPs detected in human tissues may represent precursors of calcification in the human body. 


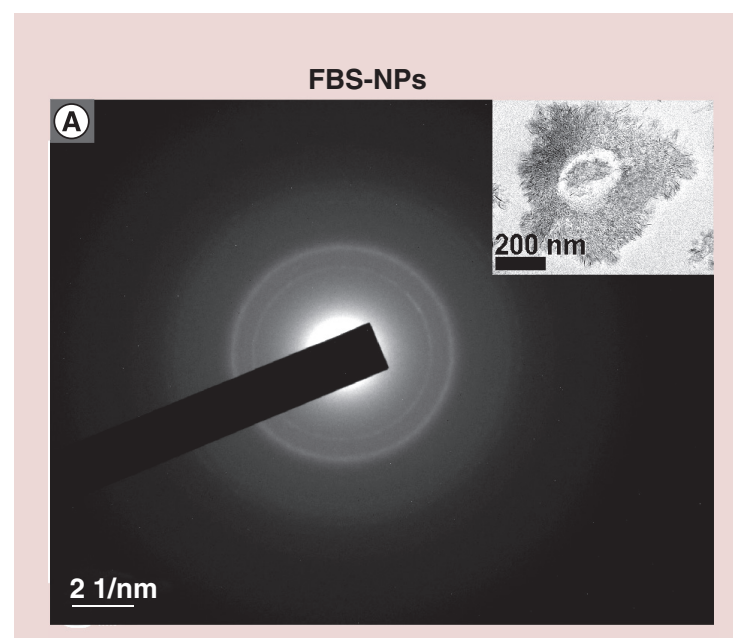

HS-NPs

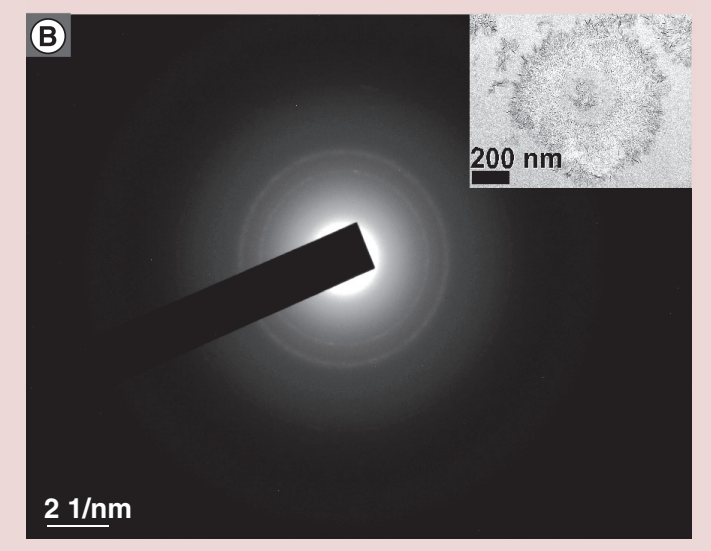

HAP

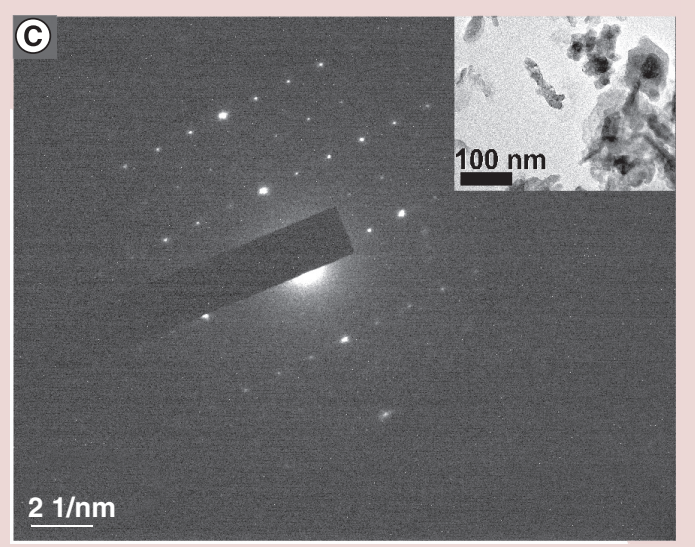

\section{Future perspective}

The analyses and techniques described in the present study may be used to study the formation of mineraloorganic NPs and to detect these particles in human tissues. Our experimental system also provides an in vitro model for studying the formation of mineral deposits similar to the ones found in calcified human tissues. Besides, albumin and fetuin-A appear to represent appro-
Figure 9. Selected area electron diffraction analysis of mineralo-organic nanoparticles. Mineralo-organic NPs were prepared as in Figure 5, using either $1 \%$ FBS (A) or $10 \%$ HS (B). The particles were prepared for thin-section TEM and SAED analysis as described in the 'Materials \& methods' section. Commercial HAP was analyzed in the same manner for comparison (C). Notice the presence of faint concentric rings showing a polycrystalline nanomaterial containing multiple crystals of relatively small sizes for FBS-NPs and HS-NPs, whereas commercial HAP produced an array of dots showing the presence of relatively large single crystals (with sizes averaging $100 \pm 50 \mathrm{~nm}$ ).

priate markers for the detection of calcium phosphate NPs in human tissues. We expect that future studies will be performed to describe in more detail the formation of mineralo-organic NPs in the human body as well as their role in human health and disease.

\section{Acknowledgements}

The authors would like to thank Willisa Liou (Chang Gung University) and Mei-Chen Chiang (Ming Chi University of Technology) for help with immunogold staining and EDX, respectively. We also thank Jyh-Ping Chen (Chang Gung University) and Chun-Chen Yang (Ming Chi University of Technology) for providing equipment and technical assistance for the DLS and AFM analyses, respectively. Acknowledgements are also due to $\mathrm{Yu}$ Hsiu Lee (Chang Gung University) for performing preliminary TEM observations related to this project.

Financial \& competing interests disclosure

This study was supported by Primordia Institute of New Sciences and Medicine, and by grants from Chang Gung University (FMRPD2T02, EMRPD1A0961), from Ming Chi University of Technology (OXBO) and from the National Science Council of Taiwan (101-2632-B-182-001-MY3). The authors have no other relevant affiliations or financial involvement with any organization or entity with a financial interest in or financial conflict with the subject matter or materials discussed in the manuscript apart from those disclosed.

No writing assistance was utilized in the production of this manuscript.

\section{Ethical conduct of research}

The authors state that they have obtained appropriate institutional review board approval or have followed the principles outlined in the Declaration of Helsinki for all human or animal experimental investigations. In addition, for investigations involving human subjects, informed consent has been obtained from the participants involved.

\section{Open access}

This work is licensed under the Attribution-NonCommercial-NoDerivatives 4.0 Unported License. To view a copy of this license, visit http://creativecommons.org/licenses/bync-nd/4.0/ 


\section{(A)}

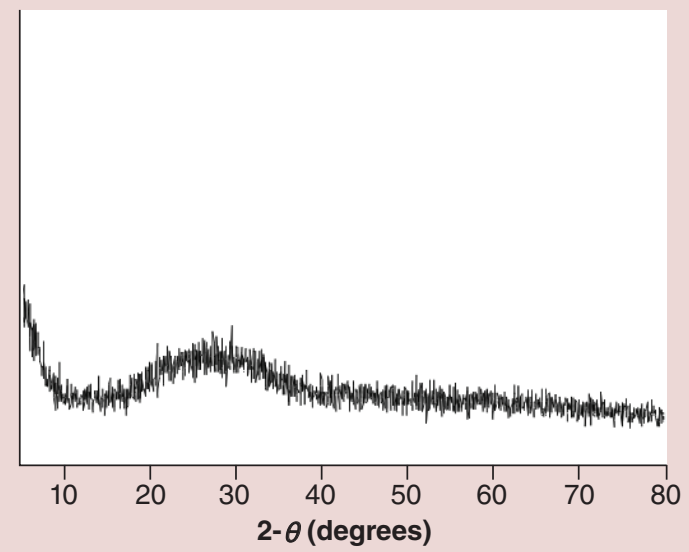

(C)

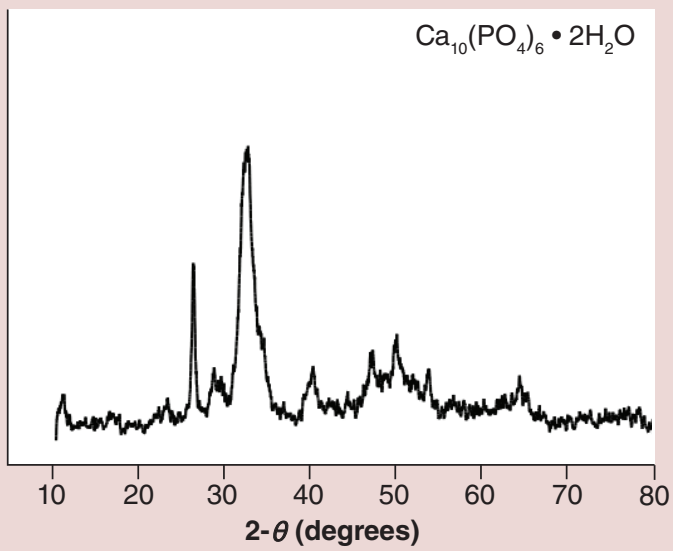

(B)

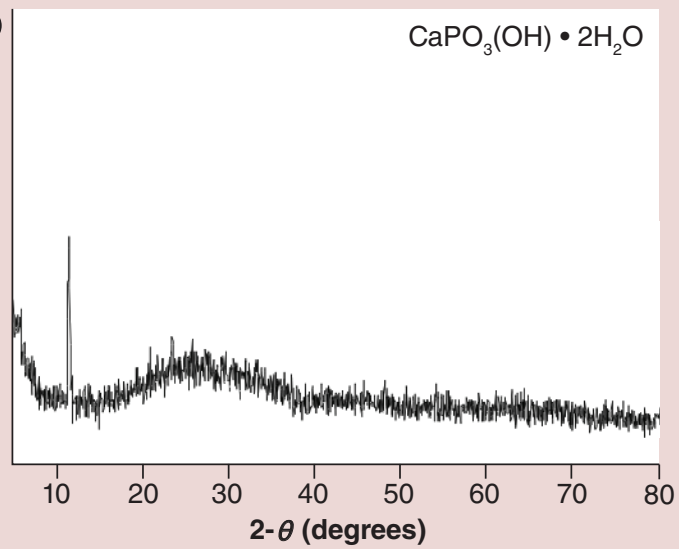

(D)

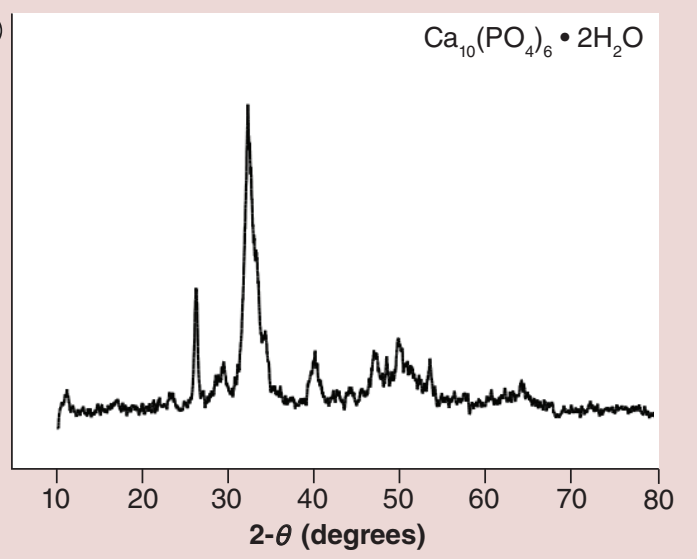

Figure 10. Powder X-ray diffraction analysis of mineralo-organic nanoparticle specimens. Mineralo-organic NPs were prepared as in Figure 5, using FBS at 1\%. Particles were analyzed immediately after precipitation (A) or following incubation for 1 day (B), 1 week (C) and 1 month (D). Following incubation, the particles were prepared for XRD analysis as described in the 'Materials \& methods' section. This XRD analysis showed that the amorphous particles obtained following precipitation in (A) gradually crystallized with time as seen with the diffraction peak observed in (B) and the multitude of peaks corresponding to HAP in (C) and (D).

\section{Executive summary}

Formation of mineralo-organic nanoparticles in biological fluids

- Mineral particles that precipitate in biological fluids form round amorphous nanoparticles (NPs) that gradually grow in size, aggregate and coalesce to form crystalline mineral biofilm-like structures.

- The mineral biofilm-like structures resemble mineral deposits observed in calcified human arteries and ectopic calcifications.

Localization of serum proteins in mineralo-organic NPs

- The serum proteins albumin and fetuin-A are associated with all growth stages of the mineral particles and are found within electron-dense areas.

Possible role of mineralo-organic NPs in the human body

- Mineralo-organic NPs detected in human tissues may represent precursors that evolve to form crystalline mineral deposits similar to the ones found in mineralized tissues and ectopic calcification.

\section{Future perspective}

- The experimental methodology employed here may be used to study the process of ectopic calcification occurring in human body fluids and soft tissues. 


\section{References}

Papers of special note have been highlighted as:

•• of considerable interest

1 Abedin M, Tintut Y, Demer LL. Vascular calcification: mechanisms and clinical ramifications. Arterioscler. Thromb. Vasc. Biol. 24(7), 1161-1170 (2004).

2 Alexopoulos N, Raggi P. Calcification in atherosclerosis. Nat. Rev. Cardiol. 6, 681-688 (2009).

3 Giachelli CM. Ectopic calcification: gathering hard facts about soft tissue mineralization. Am. J. Pathol. 154(3), 671-675 (1999).

4 Doherty TM, Asotra K, Fitzpatrick LA et al. Calcification in atherosclerosis: bone biology and chronic inflammation at the arterial crossroads. Proc. Natl Acad. Sci. USA 100(20), 11201-11206 (2003)

5 Kapustin AN, Shanahan CM. Calcium regulation of vascular smooth muscle cell-derived matrix vesicles. Trends Cardiovasc. Med. 22(5), 133-137 (2012).

6 Höhling HJ, Arnold S, Plate U, Stratmann U, Wiesmann HP. Analysis of a general principle of crystal nucleation, formation in the different hard tissues. Adv. Dent. Res. 11, 462-466 (1997).

7 Robinson C. Self-oriented assembly of nano-apatite particles: a subunit mechanism for building biological mineral crystals. J. Dent. Res. 86(8), 677-679 (2007).

-• Describes the initial observation of round calcium phosphate NPs as precursors of mineralization in developing enamel.

8 Heiss A, Eckert T, Aretz A et al. Hierarchical role of fetuin-A and acidic serum proteins in the formation and stabilization of calcium phosphate particles. J. Biol. Chem. 283(21), 14815-14825 (2008).

9 Bertazzo S, Gentleman E, Cloyd KL, Chester AH, Yacoub MH, Stevens MM. Nano-analytical electron microscopy reveals fundamental insights into human cardiovascular tissue calcification. Nat. Mater. 12(6), 576-583 (2013).

10 Martel J, Young JD. Purported nanobacteria in human blood as calcium carbonate nanoparticles. Proc. Natl Acad. Sci. USA 105(14), 5549-5554 (2008).

11 Young JD, Martel J, Young L, Wu CY, Young A, Young D. Putative nanobacteria represent physiological remnants and culture by-products of normal calcium homeostasis. PLoS ONE 4(2), e4417 (2009).

12 Young JD, Martel J, Young D et al. Characterization of granulations of calcium and apatite in serum as pleomorphic mineralo-protein complexes and as precursors of putative nanobacteria. PLoS ONE 4(5), e5421 (2009).

13 Wu CY, Martel J, Young D, Young JD. Fetuin-A/albuminmineral complexes resembling serum calcium granules and putative nanobacteria. demonstration of a dual inhibitionseeding concept. PLoS ONE 4(11), e8058 (2009).

14 Young JD, Martel J. The rise and fall of nanobacteria. Sci. Am. 302(1), 52-59 (2010).

15 Martel J, Wu CY, Young JD. Critical evaluation of gamma-irradiated serum used as feeder in the culture and demonstration of putative nanobacteria and calcifying nanoparticles. PLoS ONE 5(4), e10343 (2010).
16 Martel J, Young D, Young A et al. Comprehensive proteomic analysis of mineral nanoparticles derived from human body fluids and analyzed by liquid chromatography-tandem mass spectrometry. Anal. Biochem. 418, 111-125 (2011).

17 Peng HH, Martel J, Lee YH, Ojcius DM, Young JD. Serumderived nanoparticles: de novo generation and growth in vitro, and internalization by mammalian cells in culture. Nanomedicine (Lond.) 6(4), 643-658 (2011).

18 Martel J, Young D, Peng HH, Wu CY, Young JD. Biomimetic properties of minerals and the search for life in the Martian meteorite ALH84001. Ann. Rev. Earth Planet. Sci. 40, 167-193 (2012).

19 Peng HH, Wu CY, Young D et al. Physicochemical and biological properties of biomimetic mineralo-protein nanoparticles formed spontaneously in biological fluids. Small 9(13), 2297-2307 (2013).

20 Wu CY, Young L, Young D, Martel J, Young JD. Bions: a family of biomimetic mineralo-organic complexes derived from biological fluids. PLoS ONE 8(9), e75501 (2013).

21 Wu CY, Martel J, Cheng WC, He CC, Ojcius DM, Young JD. Membrane vesicles nucleate mineralo-organic nanoparticles and induce carbonate apatite precipitation in human body fluids. J. Biol. Chem. 288(42), 30571-30584 (2013).

- Shows that membrane vesicles found in blood may initiate the formation of mineralo-organic NPs and calcification in biological fluids.

22 Martel J, Peng HH, Young D, Wu CY, Young JD. Of nanobacteria, nanoparticles, biofilms and their role in health and disease: facts, fancy, and future. Nanomedicine (Lond.) 9(4), 483-499 (2014).

23 Wu CY, Young D, Martel J, Young JD. A story told by a single nanoparticle in the body fluid: demonstration of dissolution-reprecipitation of nanocrystals in a biological system. Nanomedicine (Lond.). 10(17), 2659-2676 (2015).

24 Kajander EO, Kuronen I, Akerman K, Pelttari A, Ciftcioglu N. Nanobacteria from blood, the smallest culturable autonomously replicating agent on Earth. Proc. Soc. Photo Opt. Instrum. Eng. 3111, 420-428 (1997).

25 Kajander EO, Ciftcioglu N. Nanobacteria: an alternative mechanism for pathogenic intra- and extracellular calcification and stone formation. Proc. Natl Acad. Sci. USA 95(14), 8274-8279 (1998).

26 Kajander EO, Ciftcioglu N, Miller-Hjelle MA, Hjelle JT. Nanobacteria: controversial pathogens in nephrolithiasis and polycystic kidney disease. Curr. Opin. Nephrol. Hypertens. 10(3), 445-452 (2001).

27 Ciftcioglu N, Mckay DS, Mathew G, Kajander EO. Nanobacteria: fact or fiction? Characteristics, detection, and medical importance of novel self-replicating, calcifying nanoparticles. J. Investig. Med. 54(7), 385-394 (2006).

28 Gilman H, Hukins DW. Seeded growth of hydroxyapatite in the presence of dissolved albumin at constant composition. J. Inorg. Biochem. 55(1), 31-39 (1994).

29 Garnett J, Dieppe P. The effects of serum and human albumin on calcium hydroxyapatite crystal growth. Biochem. J. 266(3), 863-868 (1990). 
Schinke T, Amendt C, Trindl A, Poschke O, Muller-Esterl W, Jahnen-Dechent W. The serum protein alpha2-HS glycoprotein/fetuin inhibits apatite formation in vitro and in mineralizing calvaria cells: a possible role in mineralization and calcium homeostasis. J. Biol. Chem. 271(34), 20789-20796 (1996).

31 Jahnen-Dechent W, Heiss A, Schäfer C, Ketteler M. Fetuin-A regulation of calcified matrix metabolism. Circulation 108, 1494-1509 (2011).

32 Wong TY, Wu CY, Martel J et al. Detection and characterization of mineralo-organic nanoparticles in human kidneys. Sci. Rep. (2015) (In Press).

33 Posner AS. Crystal chemistry of bone mineral. Physiol. Rev. 49, 760-792 (1969).

34 Jahnen-Dechent W. Lot's wife's problem revisited: how we prevent pathological calcification. In. Biomineralization. Bauerlein E (Ed.). Wiley, Weinheim, Germany, 243-267 (2005).

35 Jahnen-Dechent W, Schäfer C, Heiss A, Grotzinger J. Systemic inhibition of spontaneous calcification by the serum protein alpha 2-HS glycoprotein/fetuin. Z. Kardiol. 90, 47-56 (2001).

36 Schäfer C, Heiss A, Schwarz A et al. The serum protein alpha 2-Heremans-Schmid glycoprotein/fetuin-A is a systemically acting inhibitor of ectopic calcification. J. Clin. Invest. 112(3), 357-366 (2003).

-. Seminal study that identified the role of fetuin-A as a systemic calcification inhibitor in mice.

37 Herrmann M, Schäfer C, Heiss A et al. Clearance of fetuin-A - containing calciprotein particles is mediated by scavenger receptor-A. Circ. Res. 111(5), 575-584 (2012).

38 Addadi L, Raz S, Weiner S. Taking advantage of disorder: amorphous calcium carbonate and its roles in biomineralization. Adv. Mater. 15(12), 959-970 (2003). Gower LB. Biomimetic model systems for investigating the amorphous precursor pathway and its role in biomineralization. Chem. Rev. 108, 4551-4627 (2008).

- Review describing the critical role of amorphous mineral as a precursor phase in various biomineralization processes.

40 Beniash E, Metzler RA, Lam RSK, Gilbert PUPA. Transient amorphous calcium phosphate in forming enamel. J. Struct. Biol. 166, 133-143 (2009).

41 Reich W. Die Bione. Zur Entstehung des Vegetativen Lebens. Sexpol-Verlag, Oslo, Norway (1938).

42 Amos FF, Dai L, Kumar R, Khan SR, Gower LB. Mechanism of formation of concentrically laminated spherules. implication to Randall's plaque and stone formation. Urol. Res. 37, 11-17 (2009).

43 Evan AP, Coe FL, Lingeman JE et al. Mechanism of formation of human calcium oxalate renal stones on Randall's plaque. Anat. Rec. (Hoboken) 290(10), 1315-1323 (2007).

44 Ryall RL. The future of stone research: rummagings in the attic, Randall's plaque, nanobacteria, and lessons from phylogeny. Urol. Res. 36, 77-97 (2008).

45 Bassett DC, Grover LM, Müller FA, McKee MD, Barralet JE. Serum protein controlled nanoparticle synthesis. $A d v$. Funct. Mat. 21(15), 2968-2977 (2011).

46 Chen XR, Bai J, Yuan SJ et al. Calcium phosphate nanoparticles are associated with inorganic phosphateinduced osteogenic differentiation of rat bone marrow stromal cells. Chem. Biol. Interact. 5(238), 111-117 (2015).

47 He G, Gajjeraman S, Schultz D et al. Spatially and temporally controlled biomineralization is facilitated by interaction between self-assembled dentin matrix protein 1 and calcium phosphate nuclei in solution. Biochemistry 44(49), 16140-16148 (2005).

48 Schwartz MK, Hunter LW, Huebner M, Lieske JC, Miller VM. Characterization of biofilm formed by human-derived nanoparticles. Nanomedicine (Lond.) 4(8), 931-941 (2009). 